\title{
An Assessment of Basic Education under the Social Action Plan in Pakistan ${ }^{1}$
}

\author{
Shahrukh Rafi Khan*
}

\begin{abstract}
Educational expenditure as a percentage of GDP has indeed been protected and over the first phase of SAP (1993-1996) has increased by about 0.2 per cent of GDP. However, despite SAP protection, it declined to the preSAP level for 1998-99. While there is evidence that, in some aspects, the gender and regional gaps have closed, the poorest continue to be excluded from schooling, the rural female income gap in schooling has widened and, if the poor do attend, they are the most likely to drop out. Also, net enrollment rates for boys and girls actually declined over the first SAP period.
\end{abstract}

\section{Introduction}

The justified fear of austerity imposed by structural adjustment is that the social sectors, including education, are likely to face the first and major budget cuts. This fear was based on experience in several developing countries and this led to an important critique by Cornia, Jolly and Stewart (1987) who urged, as implicit in the title of their book, Adjustment With a Human Face. An important finding of their analysis was that structural adjustment was associated with the neglect of the social sectors and the poor and thus their main recommendation was reversing this neglect.

In Pakistan, the Bank's effort to put a human face on structural adjustment has come in the form of the Social Action Programme (SAP). The bulk of SAP funding has been that of the Government (see below) and one stated concern is redressing the poor performance of the social sector relative to the economic sectors and relative to a reference group of South Asian countries. ${ }^{2}$ Other stated objectives of SAP include improving efficiency, quality and closing the regional gender and income gaps in education access and attainment. ${ }^{3}$

\footnotetext{
* The author is the Executive Director, Sustainable Development Policy Institute (SDPI), Islamabad.

${ }^{1}$ This research was supported by a grant from The Asia Foundation. Many thanks are due to Sajid Kazmi for able research assistance.

${ }^{2}$ On both disparities see Banuri et.al. (1997, Chapter 3 and Chapter 6).

${ }^{3}$ For an official statement see Government of Pakistan, (1994, pp. 137-144) and (1998, pp. 16-17). For the Bank perspective see World Bank (1998).
} 
The social services targeted by SAP include basic education, primary health, population and welfare, and rural water supply and sanitation. ${ }^{4}$ Within the context of this programme, the first Social Action Programme Project (SAPP-I), with partial donor support, had a three-year duration from 1993-1996. The second project (SAPP-II, 1996-2000) is now being implemented.' SAP is now the major provider of rural primary schooling. Under the auspices of SAPP-I, between 1993-96, 15,487 new primary schools were planned and 13,356 actually built. In addition to these , 6,319 new classrooms were built and 5,794 buildings built for shelter-less schools. SAPP-II has been launched with an estimated expenditure of Rs. 270 billion (of which 65 per cent is allocated to basic schooling) compared to the Rs. 103.6 billion expenditure on SAPP-I. This represents a substantial increase in real terms. ${ }^{6}$

The main purpose of this paper is to review secondary data to ascertain the extent to which the Social Action Plan is attaining its objectives in the education sector. In the second section, we discuss SAP in a broader conceptual context and briefly describe the data, in the third section, we review educational expenditure patterns under SAP, in the forth section, we more directly review the attainment of various SAP objectives and we end with a concluding section.

\section{Conceptual context and data}

The World Bank clearly views SAP as part of a poverty strategy that has two planks. The first is to enhance growth and the second is to invest in human capital to enable people to respond as new opportunities emerge. ${ }^{7}$ To elaborate, the two-pronged approach to poverty alleviation is first, to assure that there is economic growth, which is assumed to create jobs, and

\footnotetext{
${ }^{4}$ SAP is the overall Government initiated Social Action Programme while SAPP-I and SAPP-II are the first and second partially donor funded Social Action Programme Projects that interact with SAP.

${ }^{5}$ Government expenditure was about four-fifths of the total for the Social Action Programme Project (SAPP-I, 1993-96) and the rest was contributed by the World Bank, the Asian Development Bank, the Netherlands Government and DFID. The additional donors for SAPP-II are the European Union, Canadian International Development Agency (CIDA), Norwegian Aid Agency (NORAD) and the Japanese Overseas Economic Cooperation Fund (OECF). About 7 per cent of the total is to be contributed by the beneficiary communities. The Bank's pledge of $\$ 250$ million is the largest and the Multi-Donor Support Unit is also housed in the World Bank compound. Sources for this information are SPDC,(1998, p. 44) and The News International, Friday, May 29, 1998, p. 13.

${ }^{6}$ Government of Pakistan, (1997).

${ }^{7}$ World Bank (1994, p. 2).
} 
second, to ensure that the poor are contenders for these jobs, since human capital investments in them are designed to make them more productive.

Thus the SAP project is designed explicitly to reduce poverty and misery by improving human capital access for the poor. One could argue that investments in human capital, to ensure that the poor become better market players, is a long run hands off approach to poverty alleviation. First, it hopes to get rid of poverty among future generations and thus ignores the current poor. Second, even if poor households are reached by SAP like initiatives, given the high unemployment rates and various social and institutional distortions, there is no guarantee they will find jobs even if they are more productive. ${ }^{8}$ Thus central to a sensible poverty strategy must be the creation of sustainable livelihoods. ${ }^{9}$ Here it would be difficult to wean the Bank away from its ideological compulsions.

The Federal Bureau of Statistics, Pakistan (FBS) has started conducting annual surveys called the Pakistan Integrated Househoold Surveys (PIHS). The stated objective is to provide "household and community level data which can be used to monitor, evaluate and assess the impact of the Social Action Programme." The FBS presents reports based on the data collected from large national data sets. The Round 2, 1996-97 (nd.) Report was prepared within an impressive two months of the completion of the data collection process of a survey of 12,622 respondents. Not only has the FBS demonstrated efficiency with regard to the regular data collection, it has also demonstrated a welcome analysis capacity as evident from the reports which contain a wealth of data in tabular form and some basic reporting. ${ }^{10}$ All the relevant sampling and data collection information is carefully reported. For those wishing to probe further, the primary data are easily accessible on diskette. This paper is based on the tables reported in the PIHS 1996-97 and other secondary government data available in statistical reports.

\section{Educational expenditure, patterns and outputs}

One of the major fears of structural adjustment is that the austerity it imposes to contain the budget deficit results in cuts in social sector development and recurring expenditures. In Pakistan, as earlier indicated, the Social Action Programme (SAP) has been designed to protect the social

\footnotetext{
${ }^{8}$ The scarcity of jobs give rise to social institutions such as patronage jobs which in turn have a negative impact on incentives to acquire education.

${ }^{9}$ Amalric (1998).

${ }^{10}$ The FBS has also put out a much more sophisticated report [FBS (1998)] on education to which we also refer. This analyses demand and supply side determinants of schooling based on the 1995-96 PIHS data set.
} 
sectors. It is, however, possible that while expenditures on elementary education increase, those to other levels of education decrease. In this case, SAP expenditures would not represent an "additionality" in educational expenditures but merely a re-structuring. We present the total allocations to the education sector as a percentage of GDP in Table-1 below.

Table-1: Expenditure on education as a percentage of GDP

\begin{tabular}{cc}
\hline Year/Expenditure & $\begin{array}{c}\text { Education expenditure as } \\
\text { a percentage of GDP }\end{array}$ \\
\hline $1988-89$ & 2.4 \\
$1989-90$ & 2.2 \\
$1990-91$ & 2.1 \\
$1991-92$ & 2.2 \\
$1992-93$ & 2.2 \\
$1993-94$ & 2.2 \\
$1994-95$ & 2.4 \\
$1995-96$ & 2.4 \\
$1996-97$ & 2.5 \\
$1997-98$ & 2.3 \\
$1998-99$ & 2.2 \\
\hline
\end{tabular}

Source: Government of Pakistan, Economic Survey 1998-99, Statistical Appendix, p.7.

Table-1 above reports information on educational expenditures from 1998-89 onwards, which could be considered the first fiscal year of the intensive phase of structural adjustment for Pakistan. The first fiscal year reflecting SAP expenditures is 1993-94. Between these two years, total educational expenditures as a percentage of GDP declined, but subsequently picked up and there is a 0.2 percent increase between the benchmark SAP year and the final year of SAPP-I. However educational expenditure has subsequently declined once again to the pre-SAP level despite SAP protection.

Aggregate numbers can mask many interesting details, and so it is useful to probe deeper to see how the numbers above translated into a change in facilities for basic education over the structural adjustment and 
SAP years. Unfortunately, the data do not allow probing in much depth but, again at an aggregate level, it is possible to see the changes in the rural student-teacher and student-institution ratios over time by gender as reported in Table- 2 below.

Table-2: Rural student teacher and student institution ratios by level, gender and time

\begin{tabular}{c|cccc|cccc}
\hline Year & \multicolumn{4}{|c|}{ Primary } & \multicolumn{4}{c}{ Middle } \\
\hline & STRb & STRg & SIRb & SIRg & STRb & STRg & SIRb & SIRg \\
\hline $1988-89$ & $36: 1$ & $39: 1$ & $81: 1$ & $113: 1$ & $34: 1$ & $28: 1$ & $341: 1$ & $243: 1$ \\
$1989-90$ & $36: 1$ & $40: 1$ & $88: 1$ & $112: 1$ & $36: 1$ & $27: 1$ & $367: 1$ & $252: 1$ \\
$1990-91$ & $39: 1$ & $40: 1$ & $86: 1$ & $118: 1$ & $38: 1$ & $26: 1$ & $372: 1$ & $244: 1$ \\
$1991-92$ & $35: 1$ & $39: 1$ & $87: 1$ & $118: 1$ & $39: 1$ & $25: 1$ & $386: 1$ & $243: 1$ \\
$1992-93$ & $40: 1$ & $48: 1$ & $88: 1$ & $121: 1$ & $51: 1$ & $31: 1$ & $303: 1$ & $197: 1$ \\
$1993-94$ & $39: 1$ & $46: 1$ & $88: 1$ & $126: 1$ & $54: 1$ & $28: 1$ & $315: 1$ & $216: 1$ \\
$1994-95$ & $39: 1$ & $49: 1$ & $88: 1$ & $134: 1$ & $51: 1$ & $35: 1$ & $352: 1$ & $242: 1$ \\
$1995-96$ & $40: 1$ & $52: 1$ & $89: 1$ & $131: 1$ & $41: 1$ & $34: 1$ & $307: 1$ & $222: 1$ \\
$1996-97$ & $41: 1$ & $56: 1$ & $89: 1$ & $135: 1$ & $41: 1$ & $36: 1$ & $289: 1$ & $217: 1$ \\
\hline
\end{tabular}

Source: Government of Pakistan, 1996-97, Statistical Appendix (pp. 205207).

Notes: STRb: Student-teacher ratio (boy)

STRg: $\quad$ Student-teacher ratio (gir1)

SIRb: Student-institution ratio (boy)

SIRg: $\quad$ Student institution ratio (girl)

One could view both ratios as very crude indicators of quality in so far as lower ratios indicate less crowding on an aggregate level. At the primary level, student-teacher ratios for both genders have increased since the on-set of structural adjustment, but much more sharply for girls. Such a rise accords with Bank research suggesting that ratios can be as high as 45:1 without impairing teaching efficiency. ${ }^{11}$ While the average boy ratio of 41:1 in 1996 was below this threshold, the average girl ratio of 56:1 should be a cause of great concern. Again, student-institution ratios have been rising for

${ }^{11}$ Carnoy (1995, p. 662) and World Bank (1997, p. 18). 
both boys and girls since 1988 and, once again, more sharply for girls than boys.

At the middle level (classes 5-8), the boy student-teacher ratio jumped to as high as $54: 1$ in 1993-94, but then subsequently declined to 41:1. The middle level girl student teacher ratio rose from the base of $28: 1$ in 1988-89 to $36: 1$ in 1996-97. The middle level students per institution fluctuated, but declined from the base year numbers of 341 and 243 to 289 and 217 respectively, in the terminal years (for boys and girls). Even with multiple sections, despite the improvements, these numbers appear to be extremely high for institutions covering three class years. The tables above indicate that more teachers for girl's primary schools and more institutions for both genders at the middle level are likely to be priorities in several areas. We revisit the quality and crowding issue in section IV.c, and turn now to a more direct review of the attainment of SAP objectives.

\section{Assessing the Social Action Programme objectives}

\section{A. Closing the age, gender and regional gaps}

The data on population that has ever attended school by age shows that there is now a strong demand for schooling. Overall, 83 per cent of the boys and 60 per cent of the girls in the 10-14 age cohort have attended school at some point $(90$ per cent and 80 per cent respectively in urban areas). Thus the potential to raise educational attainment by providing quality schooling is high.

There was also a strong inverse association of school attendance by age and this association has become more prominent over time. Thus school attendance for the younger cohorts was much higher $(72$ per cent for the 10-14 age group compared to 20 per cent for the 60 plus age group). More important, the gender and regional gap was much smaller for the younger cohorts. The gender gap in urban and rural areas for the 10-14 age cohort was 11 per cent and 36 per cent compared to 76 per cent and 88 per cent respectively for the 60 plus age cohort. Similarly, the urban/rural differential among those ever attending school was 11 per cent and 36 per cent in the 10-14 age cohort and 51 per cent and 75 per cent among the 60 plus cohort. Thus, while in absolute terms the percentages need to be higher, the age differential and the closing of the gender and regional gaps are encouraging. These trends are also evident from data on primary school "completers".

The above analysis pertains to progress over a time period that begins much before but includes the SAP period. There is no discontinuity 
as such observable in the data. There is however an interesting additional finding over the SAP period evident from juxtaposing the percentages in the youngest cohort that "ever attended school" with an older cohort which "completed the primary level" some years later. In 1991, 84 per cent boys and 53 per cent girls in the 10-14 age cohort had ever attended school. This is roughly the cohort that would be in the 15-19 age cohort in 199697. In the latter year, 70 per cent boys and 46 per cent girls were reported as completing the primary level in the 15-19 age cohort.

This finding is interesting for several reasons. First, it shows that the implied dropout rate was much lower than the mythical 50 per cent that is frequently cited in the press and even scholarly publications. ${ }^{12}$ Second, the implied drop out rate seems to be lower for girls. It was possible to investigate this issue more directly by looking at data on primary school "completers" among the 10-18 age cohort for 1996-97. Non-completion among girls at 8 per cent was lower than 13 per cent non-completion for boys in the urban areas. However, in rural areas, the non-completion for girls at 25 per cent is higher than the 17 per cent non-completion for boys. However, it is still much less than the generally stated overall 50 per cent non-completion ${ }^{13}$.

While there have been some SAP successes, there are also significant failures. Between 1991 and 1996-97, the net rural primary enrollment rate for boys declined from 50 per cent to 43 per cent and that for girls declined from 31 per cent to 30 per cent. Over the same period, urban boy and girl net primary enrollments declined from 61 per cent to 56 per cent and from 57 per cent to 55 per cent respectively. ${ }^{14}$ Since improving rural enrollments

12 Haq and Haq (1998, p 51) suggest that 50 per cent of children drop-out before completing the primary level and SPDC (1988, p. 50) similarly suggests the presence of a very high drop-out rate. This impression is probably based on earlier research. Khan, Siddiqui and Husain (1987, p. 9) showed very high cumulative drop out rates for 197879 / 1982-83 using provincial class level data and the cohort method to compute drop-out rates. For example, for rural girls and boys at the primary level, these ranged from 54 per cent to 80 per cent and 42 per cent to 75 per cent across the four provinces.

${ }^{13}$ The highest reported drop-out rate is 47 per cent for rural girls in class 6 . This is roughly the time girls reach puberty and many parents still withdraw girls from school at this time in their lives.

${ }^{14}$ Gross enrollment rate is defined as the number of children attending the primary level (i.e. class $0-5$ ) divided by the number of children in the 5-10 cohort, converted into a percentage. Net enrollment rate is defined as the number of children in the 5-10 age cohort attending the primary level divided by the number of children in the 5-10 age cohort converted into a percentage. Thus, while the World Bank (1998) claims success for SAP by concentrating on gross enrollments, net enrollment rates are a more precise indicator of educational success. Note that it is possible for total absolute enrollments and gross enrollment rates to rise while net enrollment rates are declining. 
in general, and those of girls specifically, was identified as a major SAP objective, this is a glaring shortcoming. Also, the regional gap for boys became larger and net girl enrollment rate actually declined in the rural areas at the primary level. This failing is actually understated since the net rural enrollment rates reported do not include non-government schooling.

Table-3 below reports on the relative growth of absolute primary enrollments in government and non-government schools.

Table-3: Estimated enrollments and enrollments growth at the primary level by type of school and gender

\begin{tabular}{l|cc|cc|cc}
\hline & \multicolumn{2}{|c|}{1991} & \multicolumn{2}{c|}{ 1995-96 } & \multicolumn{2}{c}{ Percentage growth } \\
\hline & Girls & Boys & Girls & Boys & Girls & Boys \\
\hline Govt. & 2.63 & 5.00 & 3.23 & 5.18 & 23.20 & 3.6 \\
Non-Govt. & 0.20 & 0.26 & 0.32 & 0.59 & 60.50 & 130.90 \\
\hline
\end{tabular}

Source: Government of Pakistan (1998, p.23).

First, since is possible for absolute enrollments (numerator) growth to be positive while the net enrollment growth rate is negative (see footnote 14), the numbers in Table- 3 do not contradict the numbers reported above indicating the decline in net enrollment rates. Second, non-government enrollments grew far more rapidly than government sector enrollments, particularly for boys. Third, while non-government enrollments at 11 per cent for boys and 10 per cent for girls in 1995-96 still represent a small fraction of total enrollments, the trend shows that non-government enrollments are growing rapidly. Finally, this rapid growth rate in nongovernment enrollments understates the poor growth performance of government sector net enrollment rates. Another significant SAP shortcoming pertains to the inability of the education system to reach the poorest. This issue is addressed in the sub-section below. ${ }^{15}$

\section{B. Closing the income gap}

Closing the income gap in educational attainment is another major SAP objective. In all provinces, gross and net primary enrollment rates vary

${ }^{15}$ We concentrate on broad impact indicators since that is the bottom line. SAP has instituted an elaborate monitoring and evaluation system, and third party validation (by the Auditor General's office) of input, process, output and impact. For details, see World Bank (1998, pp. 6-8). 
positively with the level of income in both rural and urban areas for both genders and at both the primary and middle levels. ${ }^{16}$ To give an example, the rural primary level net enrollment rate for the upper quintile in the Punjab, the most prosperous province, was 77 and 69 for boys and girls while it was 41 and 28 respectively for the lowest quintile. ${ }^{17}$ Again, across the board, a much higher percentage of children belonging to households in the lowest quintile never attended school or dropped out if they did attend.

To get a sense of how educational attainment changed over the SAP years for the lowest income group, we looked at gross enrollment rates for girls across the five quintiles between 1991 and 1995-96 and these are reported below in Table- 4 .

Table-4: Gross primary enrollment rates for girls between 1991 and 1995-96

\begin{tabular}{l|rcc|ccc}
\hline Quintile/Year & \multicolumn{3}{|c|}{ 1991 } & \multicolumn{3}{c}{ 1995-96 } \\
\hline & Urban & Rural & Overall & Urban & Rural & Overall \\
\hline 1st. Quintile & 77 & 27 & 35 & 67 & 35 & 40 \\
2nd. Quintile & 78 & 39 & 53 & 82 & 49 & 56 \\
3rd. Quintile & 89 & 53 & 65 & 100 & 60 & 70 \\
4th Quintile & 101 & 70 & 80 & 107 & 63 & 84 \\
5th Quintile & 100 & 64 & 76 & 113 & 84 & 96 \\
Overall & 87 & 48 & 59 & 89 & 54 & 64 \\
\hline
\end{tabular}

Source: Primary data analysis based on the PIHS 1991 and PIHS 1995-96. ${ }^{18}$

Again the table above shows gross enrollment rates for girls varying positively with income group. The only group for which gross enrollments dropped over the five-year period was urban girls from the lowest income category. While, one could argue that SAP had a positive impact on gross rural female girl enrollments in the lowest income group, the income gap in gross enrollment rates between the lowest and highest rural girls' quintile

\footnotetext{
${ }^{16}$ Government of Pakistan (1998, p. 42) clearly establishes the positive and significant association of income and school attendance for boys and girls in both urban and rural areas using multivariate analysis.

${ }^{17}$ Government of Pakistan (nd, p. 33). Quintiles were derived based on per capita household consumption in Appendix-C.

${ }^{18}$ The data analysis was done by Salman Zaidi and kindly made available by Shahnaz Kazi.
} 
increased dramatically from 37 percentage points in 1991 to 49 percentage points in 1995-96 and from 31 percentage points to 46 percentage points for all girls during this period.

In mentioning reasons for why children had "never attended school" or "not completed primary school", the most frequent household response was that the schooling was too expensive. Thus for non-completion, 35 per cent of the parents mentioned this to be a reason for girls and 29 per cent mentioned it to be a reason for boys in urban areas. These percentages were 19 and 20 percent respectively for rural areas. The other important related reason cited was that the children were needed to help at home or at work. 10 per cent and 21 per cent of the parents for boys in urban and rural areas respectively and 9 per cent and 19 per cent respectively of the parents in the case of girls mentioned this. ${ }^{19}$

It is thus quite clear that if SAP wants to reach the poor and to improve the over all educational attainment, a pro-active approach would have to be used. At the moment, many poor children are either not attending or dropping out if they do attend. A more pro-active approach would include tuition wavers, free uniforms, books and other supplies for the poorest. ${ }^{20}$ Identifying the poorest would have to be the task of the school management committees (SMCs) that only include teachers and parents of children currently in school. ${ }^{21}$ Including local notables, as currently done, is meaningless since they have a very limited legitimate stake in the school and they can easily subvert expenditure targeting. ${ }^{22}$

\section{Quality}

Retention would also be more likely if the quality of public sector schooling improved. While expenditure on schooling is a very crude measure of quality, other things equal, it can provide some information. In 1996-97,

\footnotetext{
${ }^{19}$ Other less prominent reasons in explaining non-attendance and non-completion for girls were parental disapproval and distance from school. Among the important outliers was the mention of "education not being useful" for girls in rural Balochistan and for boys in rural Punjab.

${ }^{20}$ Follow-up research for investigating the impact on educational attainment of these incentives would be useful.

${ }^{21}$ For a comprehensive study of targeting, see eds. Van de Walle and Nead (1995). One lesson that emerges from this volume is that targeting is complex. In the opening piece of this volume, Sen (pp. 11-25) identifies several problems of targeting including corruption, stigma, exclusion, dependency, counter-acting behavioral changes, administrative cost and lack of political support. With regard to the targeting we propose, waiving all fees is more straight-forward than providing uniforms, books and supplies.

${ }^{22}$ Refer to Khan and Zafar (1999) for more details on community participation via SMCs in Pakistan.
} 
excluding fees, expenditures on uniforms (which is roughly identical), books and supplies, private tuition, transport and other education related expenditure per pupil in private urban primary schools at Rs. 1,520 was almost double the per pupil expenditure of Rs. 851 in government urban primary schools. There was a similar differential is rural areas (Rs. 1,229 as opposed to Rs. 670$){ }^{23}$

One could use the non-government sector as a benchmark to ascertain how the government sector was performing in 1996-97 on selected quality indicators.

Table-5: Selected quality indicators by type of school and region.

\begin{tabular}{l|cc|cc}
\hline \multicolumn{1}{c|}{ Regional } & \multicolumn{2}{c|}{ Urban } & \multicolumn{2}{c}{ Rural } \\
\hline \multicolumn{1}{c|}{ Type of school } & G & NG & G & NG \\
\hline SIR & 232 & 165 & 96 & 117 \\
SCR & 41 & 25 & 40 & 28 \\
STR & 24 & 18 & 29 & 24 \\
\% Teaching in classroom & 77 & 97 & 55 & 82 \\
\% Schools that provide desks to students & 56 & 92 & 17 & 70 \\
\% Schools with water supply & 56 & 92 & 17 & 70 \\
\% Schools with electricity & 76 & 98 & 27 & 88 \\
Women teachers as \% of total & 46 & 85 & 36 & 71 \\
\hline
\end{tabular}

Source: Government of Pakistan (1998, pp. 66-67).

Notes: The results are based on a survey of 1,227 government and 311 non-government primary schools conducted in 1995-96.

G: Government

NG: Non-Government

SIR: Student-institution ratio

SCR: Student-classroom ratio

STR: Student-teacher ratio

The sample data reported above reinforces the concern about congestion raised by the aggregate data reported in Table- 2 . The student-

${ }^{23}$ These aggregate numbers do not indicate the real duality of educational quality and social and economic opportunities these lead to when contrasting elite urban schools and cash strapped government schools; see SDPI (1995, pp. 211-213). 
classroom ratio of 40 and 41 in government urban and rural primary schools is high. However, the student-teacher ratio of 24 and 29 respectively is more reasonable. If the non-government sector is used as a benchmark, the government sector does need to improve its supply side indicators. For example, only 55 per cent of rural government primary teaching occurs in a class room compared to 82 per cent for non-government schools; 17 per cent of government schools provide desks to students compared to 70 per cent of non-government schools; 17 percent of government schools have water supply compared to 71 per cent for non-government schools; 27 per cent of government schools have electricity compared to 88 percent for nongovernment schools. Educationists believe that women teachers are more effective at the primary level. Even in this regard, non-government schools dominate in provision since 71 per cent of their teachers are female compared to only 37 per cent for government schools.

Even so, there are signs of improvement in the public sector in the past three years (1993/94-1996/97) at the primary level. Twenty one per cent of girl schools and 28 per cent of boys schools had an increase in staff, 13 per cent of girls schools and 12 per cent of boys schools had an increase in the number of classrooms, 15 per cent of girls schools and 17 per cent of boys schools had an improvement in the maintenance of the building and 47 per cent of girls schools and 36 per cent of boys schools had an improvement in the availability of books.

\section{Summary and conclusions}

One of the major fears of the World Bank and IMF 1ed structural adjustment is that austerity drives imposed to attain a fiscal balance result in massive cuts in the social sectors. Responding to critiques, the Bank has attempted to put a human face on the economic reforms it propagates and a central element of putting a human face to reform is protecting social sector expenditures. In Pakistan, the Bank led attempt at putting a human face to economic reforms has primarily taken the form of the Social Action Programme (SAP) which the Government of Pakistan has fully supported and for which it provides about four-fifths of the total funding. SAP's major goals are to protect social sector expenditures and to ensure that such expenditures result in the closing of the income, gender and regional gaps in access to social sector facilities. The first phase of SAP ran from 19931996 and the second phase of SAP (1996-2000) is now underway.

The evidence from the education sector shows that there have been some successes in the education sector during the SAP period, but that there have been dramatic failures and that a re-conceptualisation of SAP is urgently needed. Contrary to concerns that structural adjustment will result 
in cuts in social sector expenditures, educational expenditure in Pakistan has been steadily, though not dramatically, rising. Education expenditure as a percentage of GDP has risen by 0.2 per cent between the benchmark year (1993-94) and last year (1996-97) of the first phase of SAP. However, by 1998-99 it had once again declined to the pre-SAP level $(2.2$ per cent of GNP) despite SAP protection.

Aggregate analysis suggests that these expenditures have not been adequate to reduce congestion for both boys and girls at the middle level. For example, the student teacher ratio for girls at the primary level for the last year of SAPP I was 56:1. Again, student-institution ratios for both boys and girls at the middle level were extremely high even though there has been considerable progress in this regard. Despite the crowding, Pakistan has made some progress in schooling. By 1996-97, 83 per cent of boys and 60 per cent of girls in the 10-14 age group attended school at some point. Also, since such attendance is much higher among the younger than the older cohorts, it is clear that the situation has been improving over time. Thus while overall school attendance for the 10-14 cohort was 72 per cent, it was 20 per cent in the 60 plus cohort. Also, evidence suggests that dropping-out is no longer as severe a problem as it used to be. Thus noncompletion at the primary level was 13 per cent for males and 8 per cent for females in 1996-97. Evidence also shows that the gender and regional gap in schooling has closed over the SAP period. In addition to this, evidence shows that, over the last three years of SAPP-I (1993-1996), there have been improvements in various school characteristics including increases in staff and classrooms and improvement in the maintenance of the buildings and availability of books. Finally, there was a notable increase in gross enrollment rates of rural girls including of those belonging to the lowest income group.

Even so, there is still much to worry about. The net rural primary enrollment rate declined during the SAP years from 50 per cent to 43 per cent for boys and 31 per cent to 30 per cent for girls. This failing is actually more profound than it appears since it does not take into account the performance of non-government schools. Non-government enrollments grew by 61 per cent and 131 per cent for girls and boys compared to 23 per cent and 4 per cent respectively for government school enrollment growth rates. Also, government schools lag behind non-government schools in various respects. For example, only 55 per cent of rural government primary teaching occurs in a class room compared to 82 per cent for nongovernment schools; 17 per cent of government schools provide desks to students compared to 70 per cent of non-government schools; 17 per cent of government schools have water supply compared to 71 per cent for non- 
government schools; 27 per cent of government schools have electricity compared to non-government schools.

The most serious failing of SAP has been its inability to address the problem of exclusion from schooling resulting from the low income of parents. In all provinces, gross and net enrollment rates are notably higher among the higher income group households. School being too expensive or children needed to help at home or at work are the most frequently cited subjective responses explaining why children are not in school. Again, the likelihood of dropping out increases as the income of the household declines. Finally, the income gap in enrollments for both rural and urban girls has dramatically increased over the SAPP-I period. Thus, in this regard, SAP has failed in one of the main stated goals of addressing the income gap in social sector provision. The programme needs to be re-conceptualised so that the excluded are targeted. Among other approaches, fee waivers, free uniforms or a no uniform policy, free books and supplies for the poorest, implemented by parent run school management committees, may be the most effective and least susceptible to subversion and leakage. 


\section{References}

Amalric, F., 1998, 'The Sustainable Livelihoods Approach: General Approach of the Sustainable Livelihoods Project, 1995-1997,' mimeo, Society for International Development, Rome.

Banuri, T., S.R. Khan and M. Mahmood, 1997, Just Development, Karachi: Oxford University Press.

Carnoy, M., 1995, "Structural Adjustment and the Changing Face of Education," International Labor Review, Vol. 134, No. 6, pp. 653673.

Cornia, G.A., R. Jolly and F. Stewart, 1987, Adjustment with a Human Face: Protecting the Vulnerable and Promoting Growth, Oxford: Clarendon Press.

Government of Pakistan, 1994, Economic Survey 1992-93, Federal Bureau of Statistics, Islamabad.

Government of Pakistan, 1999, Economic Survey 1998-99, Federal Bureau of Statistics, Islamabad.

Government of Pakistan, nd, 'Pakistan Household Integrated Survey, Round 2: 1996-97,' Federal Bureau of Statistics, Islamabad.

Government of Pakistan, 1998, 'Education Sector Performance in the 1990s: Analysis from the PIHS,' Federal Bureau of Statistics, Islamabad.

Government of Pakistan, 1997, 'Report on Social Action Programme for Pakistan Consortium 1997-98,' Planning Commission, Islamabad.

Haq, M and K. Haq, 1998, Human Development in South Asia, Karachi: Oxford University Press.

Khan, S. R., R. Siddiqui and F. Hussain, 1987, 'An Analysis of School Leve1 Drop-Out Rates and Output in Pakistan,' Pakistan Economic and Social Review, Vol. XXV, No. 1, pp. 1-20.

Khan, S. R., and F. Zafar, 1999, 'Community Participation in Basic Education in Pakistan via Parent Teacher Associations,' unpublished paper, SDPI, Islamabad. 
Social Policy and Development Center, 1998, Social Development in Pakistan: Annual Review 1998 (Karachi: SDPC).

Sustainable Development Policy Institute, 1995, 'Nature, Power, People: Citizen's Report on Sustainable Development,' Islamabad: SDPI.

Van de Walle, D. and K. Nead, Eds., 1995, Public Spending and the Poor, Baltimore: Johns Hopkins University Press.

World Bank, 1998, 'Implementation Completion Report: Social Action Programme Project,' Poverty Reduction and Economic Management Division, South Asia, Washington, D.C.

World Bank, 1998a, 'Project Appraisal Document: Second Social Action Programme Project,' Education Sector Unit, South Asia Region, Report No. 17398-PAK, Washington, D.C.

World Bank, 1994, 'Staff Appraisal Report: Social Action Programme Project,' Population and Human Resources Division, South Asia Region, Report No. 12588-PAK, Washington, D.C.

World Bank, 1997, 'Towards a Strategy for Elementary Education,' Population and Human Resource Development Division, South Asia Region, Washington, D.C. 